\title{
On Pedagogy for Urban Design - Some ObServations
}

\author{
Tamas Lukovich PhD \\ Institute of Architecture, Faculty of Architecture and Civil Engineering, \\ Szent István University, Budapest, Hungary \\ lukovichtamas@gmail.com
}

\begin{abstract}
In the absence of any legal, political and institutional legitimacy, what can urban design do and how should future urban designers be educated? There appear to be as many questions in the subject as possible answers. However, in the last couple of decades a rather robust theoretical direction has been emerging, upon which a more responsive design practice and professional education can be placed. There is also an increasing international interest for urban design education.in the developed and rapidly developing world. The aims of the paper are to inform, to illuminate and to provoke, including the interrogation of our own values, practices and preferences.
\end{abstract}

Keywords: responsive urban design, global challenges, education programs, theory and knowledge

\section{INTRODUCTION}

So far, the education of urban designers has got relatively little academic attention in general and in Continental Europe in particular. Comparatively little has been written on the subject, while it needs critical self-reflection and broad educational innovation as a large number of fields of knowledge inform urban design (UD) in a rapidly changing and very challenging global environment. Courses in this genuine 'heterology' are still too often eclectic, solely practice oriented and ideological. Responsive training should not, in the meantime, be an ad hoc process, with considerations of expediency and/or personal whims.

In the process, however, as Cuthbert argues [1], urban designers (and their training courses) may certainly choose to neglect any attempt to understand what is going on in complex urban environments and simply design to (pre-determined) briefs. But for those, who wish to be well informed about the production of urban form and design, a robust, encompassing and substantial theoretical framework is needed. They should know how the public realm, i.e. the main medium which has physical (space and settings) as well as socio-cultural (activities and events) dimensions, is (re)produced, how it is represented and legitimated. Abandoning outdated ideologies, our knowledge needs to change to be able to effectively influence development and design to generate more human (i.e. socially more responsive) outcomes.

My paper is basically a short review of the state-of-the-art in thinking about urban design overseas (including the UK) with an educational perspective. It follows a very simple structure, as there are three main relevant questions one might seek answers for:

A) What is the scope and nature of urban design today, what is it exactly about?

B) What is the socio-economic context of urban design now-days and in the near future?

C) And then, what are the consequences of the above for educating urban designers?

Although these three questions are interrelated, an order of subsequently posing them is inevitable in order to maintain the clarity of the discussion. 
But before starting, as a prelude, it is important to clarify the general philosophy behind my thinking, too. Accordingly, university graduates' (i.e. educated professionals') primary obligation is to understand and interpret the phenomena of the surrounding world (including the demystification of the ideologies of the dominant classes) for the rest of the society, and a secondary (but not insignificant) obligation is to apply knowledge to solve problems.

\section{THE SCOPE OF URBAN DESIGN (A)}

\subsection{Profession or Discipline or Both? - Possible definitions}

Urban design has been conducted for millennia (e.g. in Gizeh), however, it only became into being as a recognisable discipline through the process of naming during the $20^{\text {th }}$ century. [2] (Actually, the first urban design conference was held in 1956 at Harvard University.) Over the last thirty years it has become in 'vogue', reflected by a number of international conferences, symposia [41], university courses and professional journals (e.g. Urban Design International, Journal of Urban Design, Polis, or Places), particularly overseas. Despite, urban design is, to some extent, still a confusing term. (Legally, any person can still call himself or herself an urban designer.) Although, it is obvious that urban design is a social practice and, in broad terms, concerned with the four-dimensional development of the built environment (where the fourth dimension is time), there are still a number of issues in both academic education and professional practice that lack full consensus and/or clarification, based on sound empirical foundations (i.e. facts).

Undoubtedly, urban design has a European artistic design tradition. [3] According to Carmona (et al) [4], UD has been historically evolving around three distinct traditions (paradigms): 1) the 'visual-artistic' (see Camillo Sitte's artistic principles or Gordon Cullen's townscape); 2) the 'social usage' (see Kevin Lynch's mental maps, or Christopher Alexander's system concept or pattern language); and 3) the 'making places' (more recently as the synthesis of the two; see Kenneth Frampton's or Christian Norberg-Shulz's phenomenological approaches). To mask the apolitical nature of this tradition, a distinct vocabulary has been used with little common meaning. [5] In place of rigorous theoretical and methodological development, often sophisticated or even 'esoteric' rhetoric is applied.

The traditional design/planning fields still tend to look at urban design in terms of product types particular to each: town planning as the distribution of land use activities and transportation networks and as development control; landscape architecture as the design of void planes between buildings; or architecture as the design of buildings in context, or designing building complexes. While recognising these views, it is about much more. [6] While many fields are concerned with the development of the public realm (or public domain, public space), urban design is an integrative design field addressing the traditional overlapping concerns of architecture, landscape architecture, civil engineering and urban planning. [6] As a process, however, is far more than the assembly of the material environment. It is also about ideology, values, politics, propaganda, symbols, communication, myths, history, (collective) memory, representation, hope, desire, endeavour, life style, etc. It is often a frustrating process, largely determined by political, social and economic forces. 
social sciences

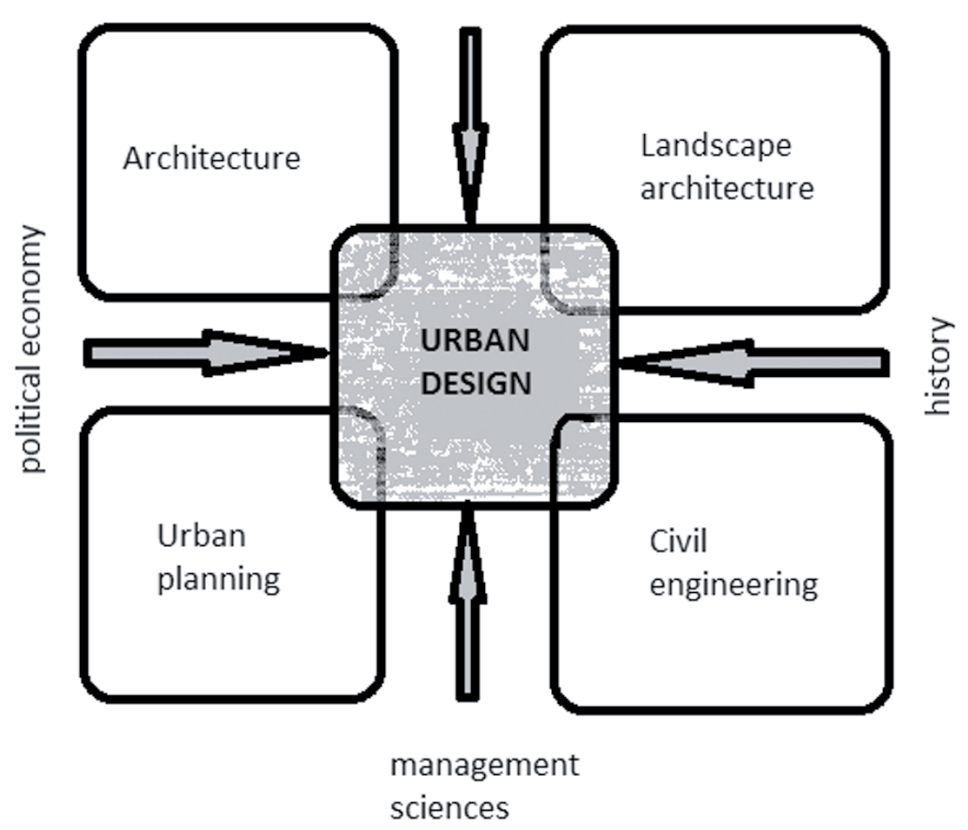

Figure 1 The 'Mandala of Urban Design': UD in relation to other design fields and contributing disciplines

By now, urban design encompasses much. Its scope is broad and expanding and its boundaries are often fussy and sometimes contested. [4] In fact, urban design as a discipline on its own has become a holistic, multi-dimensional and multi-layered (inter-, intra, multi, or cross-disciplinary) practice. It is also a collaborative art (collaboration between politicians, design professionals, citizens and between research and practice) as no single person is able to encompass all this knowledge. [6] In addition, as a creative problem solving activity (like any design field) it is also an argumentative process (with WHAT, WHY, WHERE and HOW questions) where arguments need to be based on evidence, not just expert opinions. The main sources of these evidences are empirical research, including critical (and cross-cultural) case studies.

But the problematic starts with understanding and interpreting the term 'urbanism' or 'urban'. (It was Ildefonso Cerda in the 1860's in Barcelona who coined the term 'urbanisation'.) With some simplification, there are three main possible approaches to urbanism [40, with added annotations]:

- the materialist (neo-Marxist; the dynamics of material (re)production of human life shape cities);

- the idealist (interplays between great ideas doing this; see the traditional 'City Beautiful' or other aesthetic approaches); and

- the humanist (the city as a subjective experience with ascribed meanings; e.g. semiotics, behaviourism and phenomenology).

Although, there have been many attempts, it seems that a short, clear definition simply is not possible. [7] Cuthbert argues, however, that among the many definitions Manuel Castells' early attempt $[8,9]$ stands out as a rare one that connects the process of designing cities to the overall 
process of the production, consumption, exchange and administration of space within global capitalism: 'we call urban design the symbolic attempt to express an accepted urban meaning in certain urban forms'. Amos Rapoport [10], however, looks at the design of the environment (partly) as a process of encoding information, where the users can be seen as decoding it; i.e. emphasizing its communication aspects. Denise Scott Brown [11] rather considers UD to be essentially an approach ('it concentrates more on relations, linkages, contexts and in-between spaces than on individual objects'), which deals with longer time-span, incremental growth, complex decision making. It is a 'subtle organisation of complexity; ... it requires patience' - she added.

For a profession to have any scientific basis, it must possess a real and/or a theoretical object of inquiry. Architecture has a real object (the building) and a theoretical one (the users) for inquiry, while town planning does not have any definable. Therefore architecture can claim to be both a discipline and a profession, but planning is only a profession legitimated by the state. (As a consequence, the architectural profession has, to this date, undoubtedly more authority and power than does urban planning.) Interestingly, as urban design came into existence as a practice prior to urban planning and it also has both a real and a theoretical object of inquiry (i.e. the public domain, inseparably from the idea of civil society - hence the early, somehow outdated term 'civic design' for it), it is as strong as architecture and certainly superior to planning, in terms of legitimation. [1]

We must note that urban design is not preoccupied only with big things; often it deals with rather small things (such as paving of local streets, planting of trees, regulating signs). So UD is not a question of scale, but of approach. It is important that large scale architecture is not automatically urban design; a major difference that urban design is implemented by many people (decision makers, public and private investors). In addition, it is also concerned with processes of transformation, where evolution is inherent. [1,2] Despite its role in delivering environmental quality and unlike in architecture, there are only a very few 'big names' in UD practice. In part, this is because good UD is unobtrusive, it blends and 'disappears'. [4]

To be done well, however, it needs to have a sound base of knowledge. Paul Kriesis warned designers and planners in 1963 (!) already to distinguish between facts and values (ideologies) in their work. [13] In principle, there is certainly nothing wrong with the valueladen nature of a 'collective intervention' what essentially UD is, so far the underlying values are explicitly identified/expressed, the designers involved are conscious of them and reasonable degree of meaningful public involvement is facilitated. Examples include such 'positive' ideologies as 'freedom of choice', 'sustainability', or 'open-ended design' (that allows users' personalisation).

It is difficult for a field to make progress, unless it is conceptually clear about its objectives, nature and methods. In the meantime, urban designers (similarly to the different worlds of architecture, art and politics) often try to make advantage from using terms that lack proper operational definitions and thus create rather confusion and ambiguity: e.g. 'human scale', 'vitality', 'dynamic', 'order', 'frank', 'organic'. [6] (There are certainly ones, who just do not to care about the clarity of their design vocabulary.) We need to know what we are talking about, be it the behavioural program (related to the concept of human needs), the design process, a jury, or a tutorial in school environment. 


\subsection{The need for theory}

The need for theories is perfectly clear in principle. For 1) understanding (a situation, a context, a problem, its components and their relationships, etc.) we need both to describe and to explain the particular phenomenon. It is the latter one that we need theories for. Tested, robust theories, however, are not only useful to describe and to explain, but can also predict the likely impact of a future action. And it is 1) that provides input into 2) 'prescribing' i.e. (normative) design. After all, any design is necessarily normative at the end, with a political decision component (choices among values, goals, concepts, locations, timing, advantages and disadvantages, gainers, losers, etc.). Positive (empirical) theory may provide invaluable input that might improve designing and make it more responsive. $[14,15]$ In addition, another fundamental task of theory is to guide praxis. [8] In Castells' argument, however, the ultimate aim of theory (both in urban planning and design) is to destroy the technocratic and/or utopist myths about 'the urban', and to show the ways in which the practices are articulated with social relations. [16]

We have clarified earlier that as a discipline, urban design's theoretical object is the civil society, and its real object is the public realm. Consequently, there are a large number of relevant theories that can be grouped into two main categories: procedural ones (that deal with the process of designing and/or decision making), and substantial ones (that deal with the actual design 'product' or outcome). Examples for the first type include the various theories of problem solving: associationism, Gestalt, behaviourism, the strategic choice theory or the information processing theory. [17] For the second category Maslow's theory of human needs, E. T. Hall's proximity (hidden dimensions) theory or Hillier's space syntax theory are prime examples.

\subsection{The political nature of designing}

The essence of politics is the power to control: controlling behaviour and the allocation of resources, including advantages and disadvantages (for us now, it does not matter if directly or indirectly). In fact, physical settings do the same, thus urban environments can also be interpreted as political statements. A designer (be it an architect, an engineer or an urban designer) with every line he/she draws influences, if not determines present and future users' possible behaviour (what they can and cannot do) through the 'affordances' of the environment. Just take the simplest road closure: it brutally changes the drivers' particular behaviour in that locality.

Urban design is not an independent force in urbanization and is not invented in a vacuum. [8] There are many (networks of) actors in the process of urban development. The three major categories are the suppliers of commodities (owners of land and capital), the producers (developers, local governments and various authorities, professional groups and urban designers) and the consumers (i.e. the users, practically all of us). The above differentiation helps to identify degrees and combinations of power, influence, interest and responsibility among the actors. This 'powergram' makes conflicts of values and interests visible and consequently places urban design into a political frame of reference. [18] 


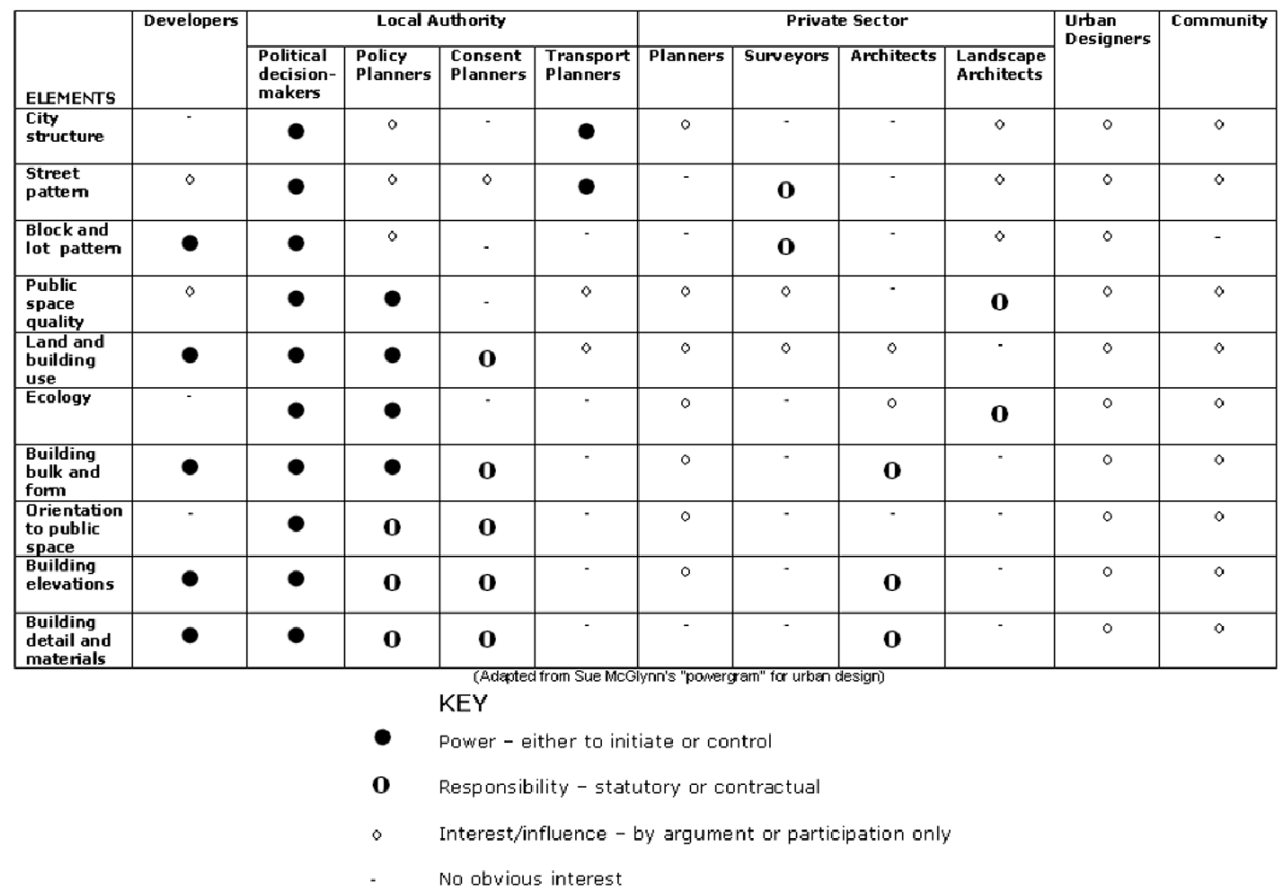

Figure 2 The 'powergram' (by Sue McGlynn) [18]

Social consciences and good intentions, however are not enough: eventually they have to be translated to actual physical form. [3] For example, one of the key features in the notion of a democratic setting is the (relative) freedom of choice. The ability to exercise choice is, however, an intricate combination of economic power, social class, education, (sub-)cultural factors, perception, personality, age, gender and health condition. The nature of urban design in democratic societies varies a great deal according to the process through its various product types are implemented. Many proposals, though, remain unimplemented for a number of reasons; be it political vagaries, unfeasible process, lack of developer interest and/or unavailable funding. Many urban designers regard issues of financial feasibility of their schemes to somehow lie outside their concerns. Considering that the budget available (and often the net income, yield, profit, too) are the central factors, this attitude is quite surprising. (Working for dictators is certainly much easier in terms of decision-making and implementation.) [6]

Finally, on my opening thesis of why contemporary urban design education, both as a discipline and a social practice, seems to get less attention in Central and Eastern Europe in general, compared to that of the Anglo-Saxon world, there are certainly a number of reasons. My non-exhaustive list of those is as follows:

- the 'language barrier' and the habit of little reading (there are still few academics and students who speak foreign languages at an adequate level to express and argue sophisticated ideas and to think about abstract philosophies, causing severe handicap in following the developments in international literature),

- $\quad$ some politically related causes (most universities are still much dependent on heavy government subsidies, and so are their departments, which make them cautious in demystifying prevailing ideologies of the often over-centralized power-structure) and as a consequence, they prefer to stay rather in the safer realm of technological/ engineering issues, 
- in addition, the presently prevailing political culture does not value independent and substantial expert input into governments decisions on urban development projects (except some at the technical level),

- the lack of systematic research (and the traditional culture of underestimating the importance of theory building and teaching). and finally

- in general, the unclarified legal and institutional legitimacy and professional status of urban design, respectively (being an integrative social practice).

As a matter of fact, presently there is not a single (independent) UD course/degree offered by Hungarian universities, except some specialisation/majors in a few architectural degree courses.

\section{THE GLOBAL SOCIO-ECONOMIC CONTEXT (B)}

The recent 'renaissance' of urban design in the developed world (i.e. a new-Mannerist era of the 'city of spectacle', with breaking the 'old rules') is largely due to the new logic of global capitalism and to the consequent new system of production and consumption of urban space. The urban spectacle and major events (world fairs, Olympic Games, Formula 1 races, world championships, fashions shows, film festivals, political summits) have become the main means of attracting capital, development, tourism and the 'desirable' classes to settle and to consume. The physical fabric of a city is also an investment and a return is expected by the investors. Architectural aesthetics have become an economic currency. [19] This economic focus was totally absent in the urban design plans up to the late 60's - early 70's. [20]

No accident that one of the strongest themes of the urban design literature of the last 30+ years is the decline of the public realm (in-between community spaces). This is primarily due to the operation of the political economy of the capitalist city with its imperative to maximise personal consumption, often at the expense of the collective good. Related to economic competition, the central ideology of western consumer capitalism is 'choice', i.e. the freedom to consume. [3]

There are many relatively new and profound challenges by the global capitalism for urban development and design in the third millennium (see Focault, Harvey, Castells, Scott, Davies, Friedman, Eco, Cuthbert and others). Just listing them in a nutshell as follows (not in order of importance):

- politics of neo-corporatism, (futile and volatile) continuous expansion of GDP, where one single country (e.g. the US) could bankrupt the planet;

- neo-imperialism reorienting the conquest of the body to that of the mind; the 'body-space' being the new geographical unit for the powerful marketing and surveillance;

- western societies consume much more than actually needed, but not only those people do that who can afford it but those, too, who cannot (resulting enormous consumer debts);

- rapid progress of new (nano, digital, robotic, gene and communication) technologies and network science, faster than society could comprehend and control them;

- variable geometry of capital, labour, production, management and markets;

- disappearing jobs (in the foreseeable future between 20-40\%) as, due to these technologies, fewer and fewer people will be needed to produce what society consumes);

- degradation of the environment and over-consumption of natural resources, unsustainable practices and life-styles;

- adaptation to climate changes, including the challenge of more and more severe natural disasters; 
- the paradox of population growth [see 44], rapidly growing third world population, inducing unprecedented global mass-migration (presently with Europe as the main focus);

- manipulated and monopolized mass media (including 'infotainment');

- compressed wealth of the world into the hands of fewer and fewer individuals, increasing disparity between rich and poor (the dichotomy of abundance and deprivation is also reflected in urban development);

- rise of religious fundamentalism and a new wave of international terrorism;

- global criminal economy (illegal trafficking of drugs, human organs, slavery, prostitution, plutonium, weapons, illegal migration, money laundering); and

- global competition between cities at all levels in the hierarchy (with winners and losers).

Space is being transformed to accommodate the new political, social and moral order. The social transformations are being reproduced in space through property relations which are articulated by the real estate sector, mediated by the design professions and reflected by the built environment. [21, 22] The built form becomes purely a commodity in itself and the public realm of the city is increasingly the arena for the consumption of signs. [3] As a consequence of economic forces, new categories of urban forms have emerged: e.g. the space of flows, 'permanent' refugee camps housing millions, new centres, heterotopias and themed environments for desire, spectacle, and impulsive consumption from Las Vegas through floating towns (gigantic cruise ships for tourists) to Dubai (after all, 'bread and circus', i.e. the organised spectacle, is an ancient, well-proved formula of social control).

In the system of accumulation, the phenomenon of theming is closely related to the notion of symbolic capital (and the aesthetics). The phenomenon, however, is not as recent as one would imagine: just take the $19^{\text {th }}$ century world's fairs, including the Columbian Exposition in Chicago in 1893. But theming, too, has undergone a series of transformations form closed commercial environments (e.g. mutating Disneylands) through whole cities (e.g. the 'real' Las Vegas in Nevada or the 'fake' Jakriborg in Sweden) to architectural movements (e.g. the New Urbanism with Seaside, Florida as its prototype project). And with tourism, they keep mutating across the whole planet. The most recent development in Dubai is creating a new class: the 'theme park of theme parks' at an incomprehensible scale. But these themed environments around us are not only saturated with the images of the past, but, as an ongoing process, with the reconstruction and transformation of the past, too. [1]

Although urban environments reflect culture that has shaped them, culture is a dynamic and non-monolithic phenomenon where there is a shift in values that influences a myriad of actions and alliances. In such a diverse environment a city provides, people must confront other people rather than reproduce an idealized view of the world, thus reaching a stage of greater psychological maturity. [23] In the process, a whole lot of dichotomies are questioned: real vs. unreal, authentic vs. inauthentic, true vs. false, right vs. wrong, morally justified vs. ethically negligent, without easy answers. In fact, not less than our value systems are at stake.

The reality is that in democratic societies, urban designers have no direct control whatsoever over such fundamental processes as population growth, migration, or economic production. In addition, architects and urban designers have only been involved in approximately $15 \%$ (!) of all actual building and construction altogether in the western world (and closer to non in third world economies). In capitalist real estate development, cost-benefit analyses (CBA) dominate any decision; their 'net present value' (NPV) and 'internal rate of return' (IRR) calculations often override any other (non-profit) considerations.

In such a stage set, what can urban design do? (Practically not much.) Where and how can it efficiently intervene? (There are very few opportunities, but where it can we must be well prepared to be effective.) And with what kind of concepts and means? 
These are challenging questions indeed that badly seek new collective professional answers and actions, respectively.

\section{EDUCATIONAL CONSEQUENCES (C)}

To begin with, there are three different aspects of any learning/teaching process: forming attitudes, providing information and developing skills, albeit with varying proportions. In educating urban designers for successful practice, all three are almost equally important for us, however, individual programs may put some more emphasis on one or on other.

A current challenge of educational programs is to develop a curricular content that will prepare future urban designers:

- to better understand the challenges and opportunities that exist in cities; and

- to enable them to identify positive interventions to improve public places.

To make the above, UD education should include a theoretical component and then make a link to practice. This means professionalizing academic knowledge. To avoid a pure ritual, connecting analysis (e.g. root-cause problems, user-environment interactions) to design is essential. One particular approach to achieve this is case study analysis, as it enhances critical thinking. [24, 20, 25]

The educational process of urban designers must be different from that of architects. [11] As Scott Brown also emphasized, great schools of urban design should stress philosophy, but philosophy of action. Urban design students (preferably with architectural or landscape architectural pre-qualification) should be kept in a 'frustrating (creative and painful) tension between a strong architecture programme and a sceptical, critical, social science based course of urban planning'. (She also added that 'architects should not be urban planners, they seem to do too many things for aesthetic reason and this is not justifiable... Who should be than? Perhaps priests, they do things for moral reasons.')

According to Cuthbert [1], there are four major systematic approaches to knowledge that can be applied to urban design:

1) Metaphysics (the philosophical foundation for an adequate theory of urban design knowledge);

2) Epistemology (the development of specific urban design methods);

3) Logic (the power of valid reasoning in urban design theory), and

4) Ethics (the basic rules of conduct for participants in the process of urban design).

While there is no meta-theory of urban design just theories in urban design, substantial critical (social) theory in the form of spatial political economy can well inform urban design, as suggested by Cuthbert $[1,2]$ and some others (e.g. D. Harvey, M. Castells, A. Scott, among others).

What is then, the structure of knowledge required by the education of an urban designer?

The main elements of this structure simply include A) sound theory/philosophy (theoretical understanding) and B) appropriate generic skills (empirical knowledge). This framework can then be filled with a combination of lecture courses, meaningful case studies and critical readers/seminars, collaborative studio work (including research, useful typologies and practical guidelines as aids) and professional internship (work experience), field work and/ or travel. There is no substitute for the leaning-by-doing, problem solving experience of the studio. Presentations, crits and juries also provide invaluable learning experiences (as UD is also an argumentative process, noted earlier). But without a strong philosophy component, the professional courses easily remain 'nuts-and-bolts affairs' that belong with vocational education, not with the university! [24] 
As to the mapping of knowledge necessary for urban design education, Moudon [26] distinguishes between normative information (prescriptive, 'what should be'. i.e. the actual process of design) and substantive knowledge (descriptive, 'what it is', i.e. understanding cities). She identifies nine concentrations of enquiry; i.e. the studies of:
1) urban history
2) picturesque (aesthetics)
3) image (meaning)
4) environment-behaviour
5) place
6) (material) culture
7) typology-morphology
8) space-morphology
9) nature ecology.

Although this is considered to be one of the best papers of its kind, the envelope it provides for knowledge still leaves out economic, political and social aspects; i.e. the dominant forces that structure the urban realm. [1] As to the social aspects, perhaps the most powerful qualitative (analytical) approaches to understanding the use of public spaces are phenomenology or participative observation. A good early example is 'The Social Life of Small Urban Spaces' study. [43]

Aspirant urban designers are, in fact, faced with subjects ('paralipomena' - 'things that have been left out', as first P. Kriesis, later Scott Brown referred to) they could not have dreamed they would be interested in: regional and urban economics, demographics, statistics, transportation/ traffic engineering, social planning, environmental psychology, cultural studies, cost-benefit analyses etc.

The praxis part then may encompass design concepts, methodology, techniques and the consequently required skills. The generic skills and competencies, necessary for good practice, include analytical, strategic, critical and lateral thinking for creative problem solving, mental flexibility (and playfulness), figural fluency, effective visual, written and verbal communication, in addition to a deeper knowledge of history (history, theory and philosophy overlap), urban sociology, cultural anthropology and social psychology. This is a tall order. (Certainly, not all single projects of different scale, complexity and nature require all of the above knowledge.)

Finding and using analogies can be a great help for creative problem solving. For urban designing, the most successful analogies include the language, the theatre and the fabrics. Another proven very efficient technique is the Disney-strategy (modelled after Walt Disney). In creative problem-solving, in fact, there are two main distinct design attitudes:

1) the use (and the adaptation) of tried \& tested types, and

2) experimental, prototypical solutions.

An important task for urban design education is to foster both with developing appropriate teaching methods for doing thorough field (site) analyses, identifying and evaluating user needs, developing behavioural programs, setting up responsive goals and objectives and with generating and evaluating feasible design alternatives, including the critical use of readers, case studies, typologies, models and various design guidelines. [20] Studio team-work and field trips (travel) are essential components, while an international project with a crosscultural perspective is a desirable one for an aspirant UD program. As to the importance of travelling, Patrick Geddes (the polymath father of urban planning) warned almost a century ago that it is the best teacher of urban planners. Since UD is directly concerned with the shape of the world, for students (and professionals, too) the real value of travelling lies in self-education: the stimulation and perspectives afforded by cultural shifts and precedents. 
It must be noted, however, that there is also a distinct approach that interprets the act of designing as being similar to initiation, (see e.g. Meggyesi) i.e. one's confrontation with his/her subconscious mind. It may provide a medium (or 'mirror') for increasing awareness and even for personal development or therapy. There are 'magic' interactions between the design and the self; a correction on the one may result in a correction on the other. Thus the process of designing can also been interpreted as a kind of 'accelerated evolution' with some pedagogical consequences.

In his seminal book series, Alexander [27] sums up a new cosmology (social-philosophy), the essence of which is also increased awareness. He argues that any design or building should be based on personal, emotional and spiritual foundations, as well. The lesson is that a designer must be able to use both hemispheres of his/her brain: the analytical, rational and the more fragile emotional, too. Connecting the two hemispheres can be particularly powerful, which, proved by neuroscience, is usually better performed by the female brain. (Despite, there still seems to be fewer female than male urban designers. As a matter of interest, the share of female authors in my reference list at the end of my paper is approximately $17 \%$ only.)

\subsection{The utility of readers}

Generally, about half of the curriculum of the best urban design programs include associated (non-design) disciplines; particularly social sciences. For studying them, however, students need to do much critical reading. To profoundly understand the intricate processes that generate urban development and are responsible for urban forms, one has to study a number of disciplines around our core subject: history, (critical) theory, aesthetics, philosophy, politics, political economy, various fields of geography, sociology and psychology, culture, gender and environment. Their relevance to urban design covers economic, financial, social, cultural and behavioural aspects. It is a myriad of sources and disciplines, in the meantime we must note that students' time and life are finite (and so are those of the teachers). So we must be selective and constantly make the right choices.

At the same time, to make urban design (and, in fact, architecture) students read is very difficult. It is traumatic to them, because they are simply unaccustomed to much reading. While it ought to be a 'must component' in their proper training, it is a real challenge. A good way of encouragement may be to emphasize that they will have little chance later on in their professional career to think about their own design philosophies and to read enough in order to develop it. Another effective tactic in introducing a new subject is to start with its history. $[20,24]$

An exhaustive list of essential readings of this true heterology is beyond the scope of this paper, if possible at all. Nevertheless, there are a few readers that, with their purposeful selection and analytical comments, complement each others to do justice to this tall order. [e.g. 28, 29, $3,7]$ However, the list of some rather classic texts, that many contemporary professionals owe a debt for encouraging their interest in urban design, is as follows:

Alexander, C. A Pattern Language and A New Theory of Urban Design;

Appleyard, D. Livable Streets;

Bacon, E. Design of Cities;

Barnett, J. An Introduction to Urban Design;

Bentley, I. et al Responsive Environments;

Broadbent, G. Emerging Concepts in Urban Space Design;

Cullen, G. The Concise Townscape;

Hall, Sir P. Cities of Tomorrow; 
Hester, R. T. Jr. Planning Neighbourhood Space with People;

Hillier, B., Hanson, J. The Social Logic of Space;

Jacobs, J. The Death and Life of Great American Cities;

Krier, R. Urban Space;

Lang, J. Creating Architectural Theory;

Lynch, K. The Image of the City, Site Planning and A Theory of Good City Form;

Mumford, L. The City in History;

Newman, O. Defensible Space;

Norberg-Schulz, C. Genius Loci;

Rapoport, A. Human Aspects of Urban Form and The Meaning of the Built Environment;

Rossi, A. The Architecture of the City;

Rowe and Koetter, Collage City;

Sitte, C. City Planning with Artistic Principles;

Spirn, A. W. The Granite Garden;

Venturi, R. (et al) Learning from Las Vegas and Complexity and Contradiction in

Architecture;

Webber, M. The Place and the Non-place Urban Realm;

Weisman, L. K. Discrimination by Design.

\subsection{The use of case studies}

Generally, case studies are well-documented and systematic examination of the process and the product. They represent the accumulated history and knowledge in different fields of human endeavours, be it medicine, law or design, in both practice and education. A set of systematic (critical and analytical) case studies [e.g. 6, 1, 30] focusing on projects (products) and on how they were generated (processes) present us with an opportunity to better understand the domain and nature of urban design.

In taking the field forward, much can be learned from the successes and limitations/failures of previous projects, but their perception depends on the perspective. Useful case studies provide comprehensive histories of projects from inception through completion to afterlife (transformation, usage and personalization). [6] Simple description of geometry, form, function, material and/or aesthetics (without context and without proper analyses) scratches the surface only, and therefore makes not much use. We should not forget their general benefit of contributing to the accumulation of structured knowledge and thus to theory building, as well.

In addition, to be able to get access to this wide range of valuable sources, students need to command English (and/or German and French) at a professional level, otherwise they cannot benefit from the abundance of accumulated knowledge and international experience.

\subsection{Typologies and models}

An abundant wealth of typologies has been available for urban designers, especially from associated disciplines. Although the concept of typology does not exclusively belong to the workbench of (urban) designers, it has permeated urban design as a problem solving tool, in regard to structures, functions and forms, throughout its history. In fact, taxonomies (that classify), typologies (that outline/classify and relate elements) and models (that represent systems with varying degree of accuracy) are three steps towards the representation of reality. Model building on the one hand is an essential part of learning, but we must keep in mind that some qualitative and subjective considerations (such as urban politics or decision making) are left out, on the other. $[31,1]$ 
The utility of developing and applying typologies and models in education (and in research) is manifold. A clear typology adds to the clarity of discussions and enables professionals and students to understand how different approaches to urban design create the various products at various scales in different socio-economic contexts. The aim is to create an information base of different design paradigms. What follows is a selection of the most significant approaches.

In the course of his outstanding academic and professional activity, Kevin Lynch offered a general typology of design already in the sixties:

- object design (single items, be it a chair or a bridge);

- project design (however large, e.g. a campus or a housing project);

- system design (functionally connected set of objects, e.g. street network); and

- city design (general spatial arrangement of activities, without the state of completion). [32]

Christopher Alexander's landmark typology [33] is basically a non-traditional 'environmental dictionary' that attempts to systematically deal with the complexity of urban environments. The Pattern Language provides 253 different patterns (like Lego building blocks) that encompass the incredible diversity of urban forms, elements, characters, settings, activities and their combinations. The essence of this approach is, however, not in these actual (physical and nonmaterial) elements, but in their complex and dynamic connections (deep structures) which were explored in later works by the author. [34,27]

There are also so called urban design paradigms dominating different historical periods and/or schools. In his essay, Chris Abel [35] offered a general typology of the models that had been traditionally used as paradigms in designing cities. He divided the fifteen analogical models, using powerful metaphors, into two groups. Formal analogies (sources of formal imagery) include:

- spiritual model

- classical model

- utopian model

- organic model

- military model

- mechanical model

- artistic model

- linguistic model

- commercial model

- identity model

- self-build model;

while process analogies cover:

- scientific model

- systems model

- semiotic model

- legal model.

Although he attempted to reduce the complexity of analogical models to a manageable set, he also argued that even when a dominant model is established, the analogical processes involved provide ample opportunity for an apparently endless variety in interpretation of the central metaphor. Three particular fields continue to contribute interesting models and interpretations: environmental psychology, mathematics and policy studies. [36]

As far as post-industrialism and themed, heterotopic environments are concerned, Appaduari [37] published an urban studies-type conceptual typology of the dimensions of 'global cultural flows' (using the term 'scape' as an analogy to form and place):

- ethnoscapes (the landscape of 'moving' persons of the shifting world; tourists, refugees, exiles, migrants, guest workers, ex-patriots, etc.) 
- technoscapes (the global configuration of the new 'fluid' technologies)

- financescapes (a more 'mysterious, rapid and difficult' [to follow] disposition of global capital)

- mediascapes (the distribution of the production and dissemination of information and the images of the world created by these media)

- ideoscapes (a chain of images and ideas related to state ideologies and counter ideologies of movements, basically for sharing some power). [1]

With a more practical orientation, an evolving typology by Lang [6] differentiates between procedures and products of urban design activities. In the first dimension, there are four major types of urban design:

- total urban design (where one team is in control of the whole project);

- all-of-a-piece urban design (where one team creates a master plan and writes guidelines

for the development of individual sites by several different developers/architects);

- piece-by-piece urban design (where proposals for an area are controlled by zoning codes, development control ordinances, bonus incentives and penalties);

- plug-in-urban design (where infrastructure elements are used as catalysts for development).

There are certainly subcategories for each. In the other (product) dimension, the categories are rather simple:

- new towns (or entire urban districts);

- urban precincts (with many new, renewed and remaining existing/old elements),

- elements of infrastructure (mainly transportation and public utilities);

- individual items, or projects (e.g. placement of monuments or works of art).

There are certainly 'catalogue' like typologies of, more or less, pure technical nature, too (covering such aspects as functions, room types, configurations, layouts, housing types, urban forms, etc.). Examples include Rob Krier's Urban Space (providing a deductive morphological framework for the diverse geometry of outdoor spaces) or Ernst Neufert's handbook on building and designing, in German speaking regions (with many editions, translated to many European languages, including Hungarian). These normative lists are mainly helpful for the inexperienced designers or students, but they are also helpful for professionals in researching historical precedents and in conducting comparative analyses.

Finally, we must keep in mind that their advantage may become and obstacle after a while in finding novel, prototypical solutions and creative new approaches to brand new problems.

\subsection{Conceptual and technical design guidelines}

As a prime example, the Urban Taskforce in the UK has developed national urban design framework with core principles and some guidelines on good design. The report also lists four kinds of contemporary UD practices:

- urban development design,

- design policies, guidance and control,

- public realm design, and

- community urban design. [38]

For the knowledge base it sets up three basic categories: contextual knowledge (cities, development processes, UD theories and principles), the activities (from analysis through design policies and actual design to implementation processes including development control), and the generic skills (creativity, graphic communication and visualisation, market awareness, interdisciplinary team working and negotiating) with sufficient details. For implementation for example, it notes six aspects of intervention: design briefing, development control, development appraisal, project funding, planning and development law, and project management. 
While various 'how to do' type normative guidelines are often not that far from design and planning manifestos (see e.g. the Machu Picchu Charter, the New Athens Charter, the Charter of New Urbanism, GLC's Housing Layout, Jacobs' and Appleyard's Towards an Urban Design Manifesto, or even Prince Charles' A Vision of Britain), the sound ones do not only provide a step-by-step recipe of 'good design', but also explicitly state their underlying concepts and ideologies. A good example is the Responsive Environments [39] by a team of academics and professionals at the (then) Oxford Polytechnics. Their underlying (naturally value laden) concept is the so called 'democratic environment' (the notion of 'democracy' projected onto the built environment, with maximising choice as a key to it). The consequent actual design qualities (permeability, variety, legibility, robustness, richness, personalization) are derived and developed from that notion, with ample illustrations how to translate those principal qualities into various design solutions.

There are some helpful, purely technical ones as well, focusing on particular aspects of creating a pleasant environment, such as the Sun, Wind and Comfort by the Environmental Simulation Laboratory of the University of California at Berkeley, for example. But even natural science based technical guidelines need regular revisions, especially related to human dimensions (as they tend to increase with subsequent generations and vary with ethnicity. climate and culture), or to global climate changes (many normative regulations still force architects to orient living rooms towards the south and the west [respectively, to the north and to the west on the southern hemisphere] in their design, while, due to climate changes, summer heath tends to make them inhabitable without effective costly air-conditioning), for example.

Summing up, guidelines are useful aids in normative actions, but might not help creativity in particularly challenging design problems.

\subsection{Leading (overseas) courses}

Finally, as far as 'what is on offer' in international (Anglo-Saxon) UD education is concerned, there are 30 different programs just in the UK, including undergraduate degree courses (rather rare), postgraduate degree (master and $\mathrm{PhD}$ research) and diploma (post-professional) courses, as well. (2016 statistics) In the US, there were more than 50 UD university courses already by the early 1990's. Since, they have multiplied, including independent MUD programs and UD concentrations/majors within various planning and architectural courses. If we take the whole geographical spectrum from Vancouver (Canada) to Auckland (New Zealand), there is an incredible choice.

An interesting option is the mechanism of joint degrees/programs (e.g. Harvard, AA School London, or Oxford Brooks). In their most flexible form, the combination is open to virtually any fields of knowledge the university (e.g. Harvard) offers. Some UD schools specialize in particular themes, such as sustainable development, property development, community design or landscape urbanism (the latter as a more recent, emerging paradigm). [42]

This flexibility and openness and the consequent inter-departmental approach are yet to be seen in most of the universities of our region, the courses of which are still based rather on 'Prussian (strict and bureaucratic) traditions'.

\section{CONCLUSIONS}

Urban space, culture and design are inseparable concepts. There should be a prevailing realism that designing cities is equal with designing culture. And culture cannot be invented, but continued only. What a responsibility! But as Cuthbert [1] argues, professional networks 
derive their authority from three main sources: from the state, from connection to (big) capital and from their command over tertiary education. Within tertiary education, professions (and the rising 'meritocracy' - with its technocrats, bureaucrats and intellectuals) tend to expropriate, monopolise and, to a large extent, mystify knowledge, in order to maintain their privileged position within the system of capitalist enterprises. 'Professionalism' in environmental professions (i.e. architecture, urban design, urban planning, landscape architecture, building, civil engineering, real estate) is, by its very nature, a profoundly political (ideological) event. The cognitive basis of their training therefore inclines them to support rather than to critique the substance of what they do. It is, in fact, almost a 'Catch 22' situation.

UD always requires acts of will on the part of the individual professionals and lay-people (citizens and politicians). Design professionals have to possess the competence to inform both politicians and the public about future possibilities, to challenge political assumptions and to follow ideas through. [6] Urban designing has become increasingly complex activity and its future (what no-one really knows) will depend on its foci of attention. But one thing is sure: the central focus of UD should be on how the public domain has been evolving, how the public space it occupies is (re)produced, transformed and designed. Certainly, each program should have its own particular focus, related to the strengths and philosophy of the institution. This will also increase choice for the prospective students and generate healthy competition among the relevant courses.

If urban design, as a discipline and a profession wishes to strengthen its identity and integrity including getting beyond its traditional role of filling in the intellectual and professional gaps between urban planning and architecture, urban designers' education must stop the practice that it can be anything anybody decides it is. Its professional actions as well as its courses (preferably on the master level) must be rooted in and informed by meaningful valid theory, if we want an intellectually sound education. There are certainly a number of options for this (from philosophy to history), but critical social theory, particularly spatial political economy (that does not separate economic development from political decisions), combined with models and methods of behavioural sciences offer to be a suitable framework for that.

There is another thing which is for sure: future courses ought to be intellectually rigorous and challenging, interdisciplinary, flexible (open for change) and responsive in both format and substance. By the way, urban design's mandate is no less than the custodianship of the much valued public realm! A final virtual 'Q\&A' (paraphrasing Le Corbusier's reaction to a question about his modulor): would all these guarantee good urban design in the future? No, it would certainly not, but it would make bad urban design more difficult. 


\section{REFERENCES}

[1] Cuthbert, A. (2006) The Form of Cities, Political Economy and Urban Design, Blackwell Publishing, Oxford.

[2] Cuthbert, A. (2011) Understanding Cities, Method in Urban Design, Routledge, London.

[3] McGlynn, S. (1993) 'Reviewing the Rhetoric' in R. Hayward and S. McGlynn eds., Making Better Places, Urban Design Now, Architectural Press, Oxford.

[4] Carmona, M. ex al (2006) Public places, Urban Spaces, Architectural Press, Oxford.

[5] Punter, J. (1990) 'The Ten Commandments of architecture and urban design', The Planner, 76 (39).

[6] Lang, J (2005) Urban Design, A typology of procedures and products, Architectural Press, Oxford.

[7] Carmona, M. and S. Tiesdall eds. (2007) Urban Design Reader, Architectural Press, Oxford.

[8] Cuthbert, A. Ed. (2003) Designing Cities, Critical Readings in Urban Design, Blackwell Publishing, Oxford.

[9] Castells, M. (1983) The City and the Grassroots. A Cross-cultural Theory of Urban Social Movements, University of California Press, Berkeley.

[10] Rapoport, A. (1990) The Meaning of the Built Environment, A Nonverbal Communication Approach, The University of Arizona Press, Tucson.

[11] Scotr Brown, D. (1990) Urban Concepts, Architectural Design Profile 60, January-February, Academy Editions, London.

[12] Pous ED. (1994) 'The Denise Scott Brown Interview, The Politics of Urban Design, Civic Space, Urban Art', Polis, No. 2.

[13] Kriesis, P. (1963) Three Essays on Town Planning, The School of Architecture, Washington University, St. Luis, Mo.

[14] Lang, J. (1990) 'Urban Design: The Collaborative Art of Shaping Cities', in T. Lukovich ed., Urban Design and Local Planning, An Interdisciplinary Approach, Proceedings of a Symposium, Environmental Planning and Management Series, Vol. 90/4, UNSW, Sydney.

[15] Lang, J. (1994) Urban Design, The American Experience, Van Nostrand Reinhold, New York.

[16] Castells, M. (1977) The Urban Question, Edward Arnold.

[17] Rowe, P. G. (1991) Design Thinking, The MIT Press, Cambridge, Mass.

[18] Hayward, R. and S. McGlynn (1993) Making Better Places, Urban Design Now, Butterworth Architecture, Oxford.

[19] Clarke, P. W, (1989) 'The economic currency of architectural aesthetics', in M. Diani and C. Ingraham eds., Restructuring Architectural Theory, Northwestern University Press, Evanston.

[20] Southworth, M. (1989) 'Theory and practice of contemporary urban design', Town Planning Review, 60 (4).

[21] GotTdiener, M. (1985) The Social Production of Space, University of Texas Press.

[22] Lefebvre, H. (1974) La Production de l'Espace, Editions Anthropos, Paris.

[23] Peponis, J. (1989) 'Space, culture and urban design in late modernism and after', Ekistics, 334/335.

[24] Ferebee, A. ED. (1982) Education for URBAN DESIGN, Proceedings of the Urban Design Educators' Retreat, Institute for Urban Design. New York.

[25] LaRa, J. J. AND S. Evans-Cowley (2016) 'Internationalizing Urban Design Education', Journal of Urban Design, Vol. 21., No.5.

[26] Moudon, A. V. (1992) 'A Catholic approach to organizing what urban designer should know', Journal of Planning Literature, 6(4).

[27] Alexander, C. (2003-2004) The Nature of Order: An Essay on the Art of Building and the Nature of the Universe, Volume 4, Center for Environmental Structure, Berkeley, California.

[28] Crow, D. ED. (1990) Philosophical Streets, New Approach to Urbanism, Maisonneuve Press, Washington, D.C.

[29] Nasar J. L. ED. (1992) Environmental Aesthetics, Theory, research and applications, Cambridge University Press, Cambridge.

[30] Benkö M. and Fonyódi M. (2009) Glocal City, Terc, Budapest.

[31] SAYer, A. (1988) 'A critique in urban modelling', Progress in Planning, 6(3).

[32] Banerjee, T. and M. Southworth ed. (1991) City Sense and City Design, Writings and Projects of Kevin Lynch, The MIT Press, Cambridge, Mass.

[33] Alexander, C. (1977) A Pattern Language, Oxford University Press, New York.

[34] Alexander, C. (1966) 'A city is not a tree', Planning, February.

[35] AвEL, C. (1988) 'Analogical models in architecture and urban design', METU JFA, 8(2). 
[36] Carmona, M. (1996) 'Sustainable Urban Design: The Local Plan Agenda', Urban DesignQuarterly, Issue 57.

[37] Appaduari, A. (2000) 'Disjuncture and difference in global cultural economy', in J. Beynon and D. Dunkerley (eds.), Globalisation: The Reader, Part B1.

[38] Detr - Department of the Environment, Transport and the Regions (2001) Training for Urban Design, www.planning.detr.gov.uk/urbandesign.

[39] Bentley, I. ET al (1985) Responsive Environments, The Architectural Press, London.

[40] SAunders, P. (1986) Social Theory and the Urban Question, Hutchinson, London.

[41] AA School of Architecture (2016) ‘Contemporary Urban Design Education', Symposium, 13 January, London.

[42] KIм, J. (2009) 'Urban Design as a Catalyst for Advancing Architectural Education', ARCC Journal, Volume 6. Issue 1.

[43] Whyte, W. H. (1980) The Social Life of Small Urban Spaces, The Conservation Foundation, Washington, D.C.

[44] Fox, R. W. (1986) 'The World's Urban Explosion', National Geography, August.

\section{Personal Note}

As antecedents to my attempt to explore the topic, I taught the subject at both some overseas and local university courses, including real life student projects/studio, organised a symposium in the interdisciplinary topic in Sydney, initiated a new postgraduate UD course at the University of NSW (and was on its working group for some time that later has become the international Master of Urban Development and Design program), published a book chapter overseas from an urban design perspective, and this was the main focus of my special study program (sabbatical leave) while visiting some of the leading schools in the US, UK, Israel and Hong Kong back in the 90's. I also organised and chaired the $7^{\text {th }}$ Biennial of European Towns and Town Planners with an urban design theme ('Making Places') in 2007.

\section{AcKnowledgement}

The author wishes to acknowledge and thank Jon Lang and Alexander Cuthbert, both professor emeritus and former colleagues at UNSW in Sydney, for their collaboration, friendship and the inspiring discussions, respectively. My gratitude also goes to Balazs Marko, Dean at the Faculty of Architecture and Civil Engineering, St. Istvan University, for providing the opportunity. 